\title{
Effect of Imidacloprid Intoxication on growth and phosphatase Activity in Soil Isolate Bacillus weihenstephanensis strain
}

\author{
A. Shetti ${ }^{1}$, B. B. Kaliwal ${ }^{2} *$ \\ ${ }^{2}$ P. G. Department of Studies and Research in Biotechnology, Davangere University, Davangere 577 002, Karnataka, \\ India. \\ ${ }^{1}$ Post-Graduate Department of Studies in Biotechnology and Microbiology, Karnatak University, Dharwad - \\ 580003, India. \\ Corresponding Author: B. B. Kaliwal
}

\begin{abstract}
Imidacloprid, , is a neonicotinoid, a class of neuro-active insecticides modeled after nicotine. The present investigation was carried out to evaluate the effect of imidacloprid treatment on growth and phosphatase activity in soil isolate Bacillus weihenstephanensis (SP-03). The soil isolate was isolated after enrichment cultures, as imidacloprid tolerant bacteria. Cells of Bacillus weihenstephanensis were exposed to imidacloprid of concentrations ranging from $10^{-7}$ to $10^{-3} \mathrm{M}$ for a period of $96 \mathrm{hrs}$. Treatment with higher dose $\left(10^{-4}\right.$ and $\left.10^{-3} \mathrm{M}\right)$ of imidacloprid caused no significant increase in the phosphatase activity, whereas, significant increase was observed in the lower dose (10-7, 10-6 and 10-5 M) of imidacloprid. The growth of the isolate was dose dependent and increase in concentration of imidacloprid lead to decreased growth. The results of present investigation revealed that imidacloprid intoxication effects the growth and development of bacteria by inhibiting metabolic enzymes and other proteins necessary for the growth.
\end{abstract}

Keywords: Bacillus weihenstephanensis, phosphatase, Growth, Imidacloprid.

\section{Introduction}

Various insecticides to protect crops against insects are been used world wide. Most insecticides are applied by spraying in large quantities, thus inducing pollution of air, soils and waters (Pimentel, 1983). The residual pesticides may become the contamination sources and pose a serious threat to the soil and groundwater environment through the rainfall infiltration process. Some pesticides act on biochemical processes that are common to many animals, plants and microorganisms, and thus are a greater hazard to non-target organisms. Many pesticides are applied directly to soil, while of those applied to crop foliage, a large percentage will also enter the soil. For example, in a field experiment where the fungicide propiconazole was sprayed onto winter wheat, $15-45 \%$ of the chemical was directly deposited on the soil surface, depending on the time of application. It has been estimated that, often, less than $0.1 \%$ of pesticides applied to crops actually reaches the target organisms (Pimental 1983).

The effect of pesticides on microbial populations is well studied, the populations from the pesticide treated plot (Aldicarb, Chlorfenvinphos, Benomyl, Glyphosate and Chlorotoluron) showed a higher rate of substrate utilization indicating grater metabolic diversity in the population. In a study the soil sample treated with Decis the total viable bacterial number was found to be higher than control and Bivistin and SDMA pesticides had no inhibitory effect on the number of total microorganisms. It is reported that Thiodan and Karate incicticides significantly reduced the fungi, actinomycetes population in the soil but bacterial numbers increased significantly (Adebayo 2007). Atrazine and atrazine and Metolachor applied in company recommended rates resulted in decrease in microbial count. Higher rate resulted in much lower microbial count. Psuedomonas Sp. and Bacillus Sp. were isolated frequently from treated samples (Ayansina and Oso, 2006). Ismail and Shamusuddin (2005) observed that after several years of application the faster break down of pesticides take place this is due to microbial adaptation to pesticides and its degradation in group or single.

Imidacloprid, 1-[(6-chloro-3-pyridinyl) methyl]-N-nitro-2-imidazolidinimine, is a neonicotinoid, a class of neuro-active insecticides modeled after nicotine. Today imidacloprid is used in over 120 countries to treat more than 140 different crops (Krohn and Hellpointner 2002; Liu et al. 2006). The high water solubility and low Koc, indicate a low tendency to be adsorbed to soil particles. Field studies show that imidacloprid can persist in soil, with a half-life ranging from 27 to 229 days. Increasing use of imidacloprid and potential toxicity among humans warrants a heightened awareness about this compound (David et al. 2007). Therefore the present investigation was carried out to evaluate the effect of imidacloprid treatment on growth and phosphatase activity in soil isolate Bacillus weihenstephanensis. 


\begin{abstract}
II. Materials And Methods
Preparation of Stock Solution of Imidacloprid

The stock solution of one molar imidacloprid was prepared and further diluted to give $10-^{3}, 10-^{4}, 10-{ }^{5}$, $10-^{6}$ and $10-^{7}$ molar concentrations. Soil isolate was isolated and identified from soil as described in our previous publication (Shetti and Kaliwal, 2012). The bacterium was maintained at $4^{\circ} \mathrm{C}$ on nutrient agar and sub cultured every fortnight. The medium used for toxicity testing was an optimized medium (dextrose $-0.65 \mathrm{~g} \mathrm{l}$ : Yeast extract - $1.05 \mathrm{~g} / \mathrm{l} ; \mathrm{K} \mathrm{HPO}-0.30 \mathrm{~g} / \mathrm{l} ; \mathrm{NaCl}-0.25 \mathrm{~g} / \mathrm{l})$.
\end{abstract}

\title{
Preparation of Inoculum
}

Pre-inoculum was prepared by inoculating a loop full of bacteria from the overnight incubated nutrient agar slant cultures on a $100 \mathrm{ml}$ sterilized optimized growth medium and incubated for 24 hours at $37^{\circ} \mathrm{C}$ under static conditions.

\section{Identification of Bacterial Isolate}

Imidacloprid tolerant colonies were isolated and identified morphologically, cultural and biochemical characterization and 16S rDNA identification was done as described earlier (Shetti and Kaliwal, 2012). The pure culture was grown on nutrient agar medium.

\section{Experimental Procedures}

Five $\mathrm{ml}$ of the pre-inoculum was inoculated to $250 \mathrm{ml}$ Erlenmeyer's flask containing $100 \mathrm{ml}$ of sterilized optimized growth medium amended with different molar concentrations of imidacloprid. The flasks were incubated at $37^{\circ} \mathrm{C}$ for 96 hours under shaking conditions at $120 \mathrm{rpm}$ on a rotary shaker. At regular intervals, sample was taken out from each flask aseptically for analysis.

\section{Growth}

The concentration of cells was measured every $24 \mathrm{hrs}$ using spectrophotometer taking optical density (OD) at $600 \mathrm{~nm}$ described by Kosmachevskaya et al., (2007).

\section{Phosphatase activity}

Alkaline phosphatase was estimated as per the procedure of Vastraete et al., (1976). Two ml of the sample or an aliquot diluted to $2 \mathrm{ml}$ was incubated with $2 \mathrm{ml}$ of tris buffer $\mathrm{pH} 8.4$ and $1 \mathrm{ml}$ of $0.1 \mathrm{mM} \mathrm{p}$ nitrophenol phosphate incubated for 4 hours and $2 \mathrm{ml}$ of the reaction mixture was added to $2 \mathrm{ml}$ of $0.5 \mathrm{~N} \mathrm{NaOH}$ and $2 \mathrm{ml}$ of $0.05 \mathrm{M}$ EDTA. OD was measured at $420 \mathrm{~nm}$ against a blank treated in the same way. The amount of p-nitrophenol released was calculated by referring to the standard graph of p-nitrophenol. The unit of phosphatase activity is the micro grams of p-nitrophenol released per minute per $\mathrm{ml}$ of the sample.

\section{Statistical Analysis}

Statistic significance between the control and experimental data were subjected to analysis of variance (ANOVA) followed by post-hoc dunnet's test ( $\mathrm{P} \pm<0.05)$.

\section{Results \\ Effect of imidacloprid on growth of Bacillus weihenstephanensis}

The optical density in Bacillus weihenstephanensis at 24, 48, 72 and 96 hrs was $0.268,0.445,0.532$ and 0.626 respectively in the control groups. On treatment with the lowest concentration of $10-7 \mathrm{M}$ of imidacloprid optical density was $0.261,0.3900 .487$ and 0.571 and the inhibition observed was $2.62,12.36$, 28.21 and $8.79 \%$ treated for $24,48,72$ and 96 hrs respectively. On treatment with 10-6 M of imidacloprid the optical density was $0.224,0.322,0.436$ and 0.495 and their corresponding inhibition obtained was $16.42,27.65$, 38.46 and $20.93 \%$ for $24,48,72$ and 96 hrs respectively. Treatment with 10-5 M concentration of imidacloprid showed the optical density of $0.189,0.285,0.397$ and 0.431 and the corresponding inhibition observed was $29.48,35.90,45.15$ and $32.16 \%$ at a given duration of $24,48,72$ and $96 \mathrm{hrs}$ respectively. At 10-4 M concentration of imidacloprid the optical density was $0.162,0.257,0.331$ and 0.390 with their corresponding inhibition of $39.56,42.25,43.97$ and $37.70 \%$ at a given duration of $24,48,72$ and 96 hrs respectively. On treatment with 10-3 $\mathrm{M}$ of imidacloprid the optical density was $0.134,0.235,0.285$ and 0.343 and their corresponding inhibition was $50.0047 .20,46.66$ and $45.21 \%$ at a given duration of 24, 48, 72 and $96 \mathrm{hrs}$ respectively.

\section{Effect of imidacloprid on phosphatase in Bacillus weihenstephanensis}

The activity of phosphatase observed in the control groups of Bacillus weihenstephanensis was 0.358 , $0.442,0.496$ and $0.578 \mathrm{U}$ at duration of $24,48,72$ and 96 hrs respectively. On treatment with $10-7 \mathrm{M}$ of imidacloprid the phosphatase activity was $0.404,0.480,0.572$ and $0.592 \mathrm{U}$ at duration of 24, 48, 72 and $96 \mathrm{hrs}$ 
respectively. Treatment with 10-6 $\mathrm{M}$ of imidacloprid showed an activity of $0.460,0.512,0.589$ and $0.628 \mathrm{U}$ at the duration of 24, 48, 72 and 96 hrs respectively. On treatment with 10-5 M of imidacloprid the phosphatase activity was $0.524,0.593,0.672$ and $0.703 \mathrm{U}$ at duration of $24,48,72$ and $96 \mathrm{hrs}$ respectively. Treatment with $10-4 \mathrm{M}$ of imidacloprid showed an activity of $0.620,0.652,0.704$ and $0.771 \mathrm{U}$ at the duration of $24,48,72$ and 96 hrs respectively. On treatment with $10-3 \mathrm{M}$ of imidacloprid the phosphatase activity was $0.646,0.716,0.772$ and $0.853 \mathrm{U}$ at duration of $24,48,72$ and $96 \mathrm{hrs}$ respectively.

\section{Discussion}

Phosphatases are enzymes, which hydrolyze esters and anhydrides of phosphoric acid contributing to increase the amount of phosphorous available; these activities have been detected in bacteria, zooplankton and phytoplankton (Petersson, 1980). Phosphatase is a nonspecific phosphomonoesterase, which removes inorganic phosphate from phosphoric esters or transfers the phosphoryl group to an acceptor hydroxyl group (Fernley, 1971). They are widely found in various organisms, indicating their important role in metabolism of different phosphorus containing organic compounds (McComb et al., 1979) and Escherichia coli phosphatase has been studied in most detail by Yerchenko et al., (2003). Phosphatases are lysosomal enzymes which catalyze the splitting of phosphoric acid from certain phosphoric esters. They help in autolysis of the degenerated cells and mediate membrane transport (De Duve et al., 1955). In a study it is reported that the presence of organochlorinated insecticides (aldrin and lindane), organophosphorous insecticides (dimetoate, methidation and methyl-parathion), atrazine (herbicide) and captan (fungicide) significantly increased phosphatase activities after 28 days of incubation. Heterotrophic mesophilic and psychrophilic aquatic bacteria counts as well as culturable phosphate solubilizing microorganisms, increased when the pesticides were added to lake water samples (Lo et al., 2006).

In the present graded dose and durational exposure study of imidacloprid it was found that the phosphatase activity in the treated groups increased significantly in higher dose $\left(10^{-5}, 10^{-4}\right.$ and $\left.10^{-3} \mathrm{M}\right)$ of exposure to imidacloprid, where as there was no significant increase observed in the lower dose $\left(10^{-7}\right.$ and $10^{-6}$ M) of imidacloprid in Bacillus weihenstephanensis. Similar results were obtained by Perisamy and Raman, (1995), who reported that phosphatase, is produced under stress conditions on exposure to toxic chemicals like heavy metals to degrade the phosphate groups of nucleic acid and this enzyme occurs in all living cells. It has been reported that elevated levels of phosphatase was observed on exposure to carbamates which may be indicative of an adaptive rise in enzyme activity in response to persistent stress. Ponmurugan and Gopi (2006) have suggested that for phosphate solubilizations, the bacteria produce the phosphatase enzyme. It has been reported that the synthesis of phosphatase takes place as an adaptive mechanism to chemical stress. It is suggested that the contaminants like metal ions, can inhibit apatite formation and growth, cell proliferation, extra cellular mineralization and specific cellular functions, such as phosphatase activity (Park et al., 2006). It has been demonstrated that, a positive correlation exists between phosphate solubilizing capacity and phosphatase enzyme activity, which may be due to the availability of higher amount of phosphorus and/ or soluble phosphates in the medium.

\section{Growth}

The term growth as commonly applied to bacteria and other microorganisms usually refers to changes in the total population rather than an increase in the size or mass of an individual organism, growth denotes the increase in number beyond that present in the original inoculum (Pelczar et al., 1993). In the present graded dose and durational exposure study, there was a significant decrease in the growth in all the groups treated with imidacloprid in Escherichia coli, Brevundimonas Sp. MJ 15 and Bacillus weihenstephanensis with an increase in the \% inhibition. Present investigation also revealed that Bacillus weihenstephanensis showed higher growth on treatment with imidacloprid than other two soil isolates. The study on growth kinetics provides an evidence of mineralization potential of organism (Lee et al., 1998). Cypermethrin and monocrotophs had adverse effect on the total number of soil bacteria (Rangaswamy and Venkateshwarlu, 1992). In a study Endosulfan inhibited the growth of $B$. subtilis in $32-80 \mu / 1$ concentrations. In the study there was no growth observed above $64 \mu / 1$ concentration of endosulfan (Tolan and Ensari, 2006). The imidacloprid might have affected the bacterial growth via possible attack to the membrane components and inhibited activity of DNA polymerase I. The increase in percent inhibition in growth with increase in dose and duration of exposure of imidacloprid in cells is obligatory since some microbial groups will be able to use an applied pesticide as a source of energy and nutrients, where as others may well be toxic to other organisms and as such the soil microbial community is a complex picture of interwoven relationships between organisms in different tropic levels (Johansen et al., 2001). It is widely accepted that bacterial cells in the natural environment exist in constant flux between short periods of exponential growth and much longer periods of non-growth. This has been termed the "Feast and Famine" existence of bacteria, when nutrient are available, bacteria can attain rapid growth rates, but when nutrients are depleted, they must be able to endure prolonged periods of starvation.( Tormo et al., 1990). 


\section{Conclusion}

The present investigation was carried out to evaluate the effect of a neonicotinoid, class of neuroactive insecticides imidacloprid treatment on growth and phosphatase activity in soil isolate Bacillus weihenstephanensis (SP-03). The soil isolate was isolated after enrichment cultures, as imidacloprid tolerant bacteria. Treatment with higher dose $\left(10^{-4}\right.$ and $\left.10^{-3} \mathrm{M}\right)$ of imidacloprid caused no significant increase in the phosphatase activity, whereas, significant increase was observed in the lower dose (10-7, 10-6 and 10-5 M) of imidacloprid. The growth of the isolate was dose dependent and increase in concentration of imidacloprid lead to decreased growth. The results of present investigation revealed that imidacloprid intoxication effects the growth and development of bacteria by inhibiting metabolic enzymes and other proteins necessary for the growth. The mechanism of imidacloprid intoxication in prokaryotes should be studied in- detail.

[1] Adebayo, T. A., Ojo, O. A. and Olaniran, O. A. (2007). Effect of two insecticides Karate and Thiodan on Population Dynamics of Four Different Soil Microorganism. R.J.B.S., 2(5), 557-560.

[2] Ayansina, A. D. V. and Oso, B. A. (2006) Effect of two commonly used herbicides on soil microflora at two different concentrations. A.J.B., 5(2), 129-132.

[3] David, D., George, I. A. and Peter, J. V. (2007) Toxicology of the newer neonicotinoid insecticides: imidacloprid poisoning in a human. Clin. Toxicol., 45, 485-486.

[4] De Duve, C., Presman, B. G., Gianetto, G., Wattiau, R. and Appelmans, F. (1955). Intra cellular distribution pattern of enzymes in rat liver tissue. Biochem J., 60, 604-617.

[5] Fernley, H.N. (1971). Mammalian alkaline phosphatases. In: Enzymes. Boyer P.D. Ed. N.Y.: Acad. Press, 4, 417-447.

[6] Ismail, B. S. and Shamsuddin, N. (2005). Effects of Alachlor and Metolachor on microbial populations in the soil. M.J.M.,(1), 3641.

[7] Johansen, K., Jacobsen, C. S. and Torsvik, V. (2001). Pesticide effects on bacterial diversity in agricultural soils - a review. Biol. Fertil. Soils., 33, 443-453.

[8] Kosmachevskaya, O. V., Shumaev, K. B., Arredondo-Peter, R. and Topunov, A. F. (2007). Influence of Tert-Butyl Hydroperoxide and nitrosoglutathione on Escherichia coli cells expressing leg-hemoglobin. Journal of Stress Physiology \& Biochemistry., 3, 18-24.

[9] Krohn, J. and Hellpointner, E.(2002) Environmental fate of imidacloprid. Pflanzenschutz- Nachr Bayer., 55, 3-26 (special edition).

[10] Lee, S. G., Yoon, B. D., Park, Y. G. and Oh, H. M. (1998). Isolation of a novel pentachlorophenol degrading bacterium, Pseudomonas sp. Bu 34. J. Appl. Microbiol., 85, 1-8.

[11] Lo' pez L, Pozo C, Rodelas B, Calvo C, Gonzalez-Lo'pez J. 2006 - Influence of pesticides and herbicides presence on phosphatase activity and selected bacterial microbiota of a natural lake system. Ecology and Toxicology 15, 487-493.

[12] McComb, R. B., Bowers, G. N. and Posen, S. (1979). Alkaline Phosphatase. (New York, NY: Plenum Press).

[13] Park, S. M. Kim, H. S. and Yu, T. S. (2006). Effect of Titanium Ion and Resistance Encoding Plasmid of Pseudomonas aeruginosa ATCC 10145. The Journal of Microbiology., 44(3), 255-261.

[14] Pelczar, M. J, Chan, E. C. S. and Krieg, N. R. (1993). In: Microbiology. Concept and Application. Tata Ed., Mc Graw- Hill Inc., New York. 281-324.

[15] Perisamy, K. and Raman, K. (1995). Effects of cu and Ni on acid phosphatase activity on ectomycorrhizal fungus, Laccaria Laccata. Ind. J. Agri.Sci., 72, 249-253.

[16] Petersson, K. (1980). Alkaline phosphatase activity and algal surplus phosphorous as phosphorous deficiency indicator in Lake Erken. Arch Hydrobiol., 89,54-59.

[17] Pimentel, D. (1983). Effects of pesticides on the environment.' 10 Intl. Congress on Plant Protection. Crydon., 2, 685-691.

[18] Ponmurugan, P. and Gopi, C. (2006). IN VITRO production of growth regulators and phosphatase activity by phosphate solubilizing bacteria. American journal of biotechnology, 5(4), 348-350.

[19] Rangaswamy, V. and Venkateswarlu, K. (1992). Degradation of selected insecticides, monochrotophos, quinalphos, cypermethrin and fenvalerate, by bacteria isolated from soil. Bull. Env. Contam. Toxic., 49(6), 797-804.

[20] Tolan, V. and Ensari, Y. (2006). Effect of endosulfan on growth, $\alpha$-amylase activity and plasmids amplification in Bacillus subtilis. Indian journal of Biochemistry and Biophysics., 43, 123-26.

[21] Tormo, A., Almiron, M. and Kolter, R. (1990). Sur A, an Escherichia coli gene essential for survival in stationary phase. J. Bacteriol., 172, 4339-4347.

[22] Yerchenko, V., Khromov, I. S. and Budilov, A. V. (2003). Thermostable alkaline phosphatase of bacterium Meiothermus rubber: Gene cloning, expression in Escherichia coli, and biochemical charecterization of the recombinant protein. Molecular Biology., 37(6), 841-848.

IOSR Journal of Biotechnology and Biochemistry (IOSR-JBB) is UGC approved Journal with S1. No. 4033, Journal no. 44202.

A. Shetti. "Effect of Imidacloprid Intoxication on growth and phosphatase Activity in Soil Isolate Bacillus weihenstephanensis strain." IOSR Journal of Biotechnology and Biochemistry (IOSR-JBB) 3.4 (2017): 53-56. 